\title{
INVESTIGATING THE NEW AND ADVANCED ENERGY CONVERSION TECHNOLOGIES IN ANALYSIS OF POWER PLANTS
}

\section{REZA FATHOLLAHI}

Department of Mechanical Engineering, Engineering Faculty of Khoy, Urmia University, Urmia, I.R. Iran

Optimization of energy conversion technologies becomes more important due to limitations of fossil fuels and the environmental impact during their use. For decades, the response to the ever-growing need for electric generation capacity was to build a new steam power plant, one not very different from the previous one. So, considering the importance of thermal power plants (steam, gas and combined cycle) as the main sources of power generation in Iran, the purpose of this study was to investigate the new and advanced energy conversion technologies to measure technical efficiency and productivity in the analysis of power plants as one of the main elements of the cycle of power plant improvement in 10 active thermal power plants at the country in the year 2011-2016. Among the studied power plants, Booshehr power plant with $4.5 \%$ positive growth in efficiency had the best scale efficiency and Shahid Firoozi power plant with $-3.8 \%$ negative growths in scale efficiency had the worst efficiency. The results of the study of the technical efficiency of 10 power plants show that the average technical efficiency of the power plants in 2016 under the assumption of VRS and CRS was 84.2, 89.8\%, respectively. So Zarand, Qom and Fars power plants have been introduced as reference plants. The results for both VRS and CRS assumptions show that combined cyclic power plants had a higher average technical efficiency than other power plants. It is recommended that power plants that use only gas turbines to generate electricity will move toward the combined cycle power plants to improve the efficiency. So most influential factor in the changes in the efficiency of selected plants is technological change, which has had a slight annual growth. Finally, in order to increase technical efficiency, which ultimately increases productivity, it is suggested that power plants provide education, advice and promotion of new technologies.

KEYWORDS: Energy Conversion Technologies, Efficiency, Productivity \& Combined Cycles
\end{abstract}

Received: Nov 23, 2018; Accepted: Dec 13, 2018; Published: Jan 02, 2019; Paper Id.: IJMPERDFEB201916

\section{INTRODUCTION}

Success in any industry requires the use of best technology and optimal utilization of the factors of production and facilities available. Therefore, increasing productivity and efficiency in all industries of the country is a surefire way to achieve more economic growth with the same resources and facilities available. Among the various industries, the power industry is dynamic and influential due to the role of infrastructure and its link with other factors affecting economic growth, and the increase of efficiency and productivity in this industry is very important.

Generally the power industry is divided into three parts: production, transmission and distribution. In the meantime, the power generation sector is the most important and, at the same time, the capital of the leading sector in the electricity industry. Power plants can be divided into three categories of hydroelectric plants, wind farms and thermal power plants, according to the energy sources needed to generate electricity. Conventional power plants in Iran are thermal power plants (steam, gas and combined cycle) and water power plants. Our country has a 
comparative advantage due to the rich resources of oil and gas (as the main fuel of steam, gas and combined cycle power plants).

Optimization of energy conversion technologies becomes more important due to limitations of fossil fuels and the environmental impact during their use. For decades, the response to the ever-growing need for electric generation capacity was to build a new steam power plant, one not very different from the previous one. The energy conversion engineer is faced with a variety of issues today: emerging technologies, changing social and technological climate in which a diversity of approaches is likely to be accepted. Another key problem facing the energy conversion engineer is the finiteness of natural resources critically important for human beings (such as natural gas and oil) in the world and ever-increasing energy demands by developing countries.

Energy conversion technologies considered as a system that converts energy from one state to another state. Energy can be described in many ways, with different forms of energy, including heat, work, motion, potential energy in the form of nuclear, chemical, elastic or gravitational, and radiant energy also known as light. The total of this converted into useful energy, with the one of the most important and suitable forms of electricity (Wolfson, 2012).

Many of the energy converters broadly applied technologies such as the conversion of thermal energy into electrical energy. The efficiency of these technologies is the main problem for major restriction, as presented by the laws of thermodynamics and other scientific principles. Recently, considerable attention has been paid to specific direct energy-conversion technologies, especially solar cells and fuel cells that bypass the intermediate step of conversion to heat energy in electrical power generation.

This study investigates the development of energy-conversion technology, as well as addressing not only conventional systems but also experimental converters with considerable potential. It shows their distinctive features, basic principles of operation, major types, and key applications. For a discussion of the laws of thermodynamics and their impact on system design and performance, see thermodynamics.

The energy conversion technologies in a coal power plant are a thermodynamic process. The development of energy efficiency in a thermodynamic process generally relays on energy analysis of the process that determine measures needed to be considered. The conventional method of energy analysis is based on the first law of thermodynamics, which focuses on conservation of energy. The limitation with this analysis is that it does not consider properties of the system environment. Hence, the first law analysis considered about the performance of energy conversion technologies. Reach to higher efficiency, so, a higher order analysis based on the second law of thermodynamics as this enables us to determine the main resources of loss, and reveals avenues for performance improvement.

Production always requires production factors. Increasing production can be achieved by two methods of increasing the factors of production and better use of the factors of production by adopting a better management of these resources and employing newer methods of their combination. One of the ways to optimize the combination of factors of production is to use concepts of efficiency and productivity. Efficiency and productivity are the criteria by which they can continually improve existing conditions. The first step in the cycle of improving efficiency and productivity is measured. Measurement of efficiency and productivity as an appropriate system provides the conditions for decision makers to understand what status they are and can plan to improve the current situation.

Song et al (2014) conducted a study entitled analysis of energy efficiency for coal-fired power units based on data 
envelopment analysis model. In this article, the non-parametric data envelopment analysis method DEA is employed to evaluate energy efficiency of coal-fired power units in China. The data consisted of inputs and outputs of 34 coal-fired power units. The value of CCR efficiency determined based on two input parameters: fuel consumption and auxiliary power consumption. The relations between EE and factors such as a parameter of main stream, cooling method, capacity utilization rate and annual utilization hours are analysed. Some relation curves are fitted (Song et al, 2014).

Yieth Chen et al (2013) addressed data envelopment analysis (DEA), such as undesirable CO2 emissions outputs to examine power plants source utilization efficiency within 73 countries to incorporate the global warming effect. They founded that Asia reveals the highest technical efficiency and European countries restrict from the lowest technical efficiency. They show 3 hypotheses to investigate gross national product (GNP), urbanization, and electricity import level factors that potentially affects power plants efficiency by Tobit regression analysis. The findings reveal that GNP and urbanization have effects on power plants efficiency except electricity import level (Yieth Chen et al, 2013).

Hadizadeh et al (2017) declared heating and cooling loads are determined for experimental model development for combined cycle power plant of Parehsar, located in province Guilan. So, according to this model, thermal energy required for heat supporting of absorption, thermal generator is calculated and the proper chiller is chosen to secure cooling of model spaces. In addition, for the actual study, the portion of low and high pressure steam of heat recovery steam generator (HRSG) and Turbine is examined. The findings reveal that the steam extraction of HP-Turbine approach is more effective than the other methods for developing the power planet energy efficiency. Hence, parametric study shows the effects of different parameters, such as steam to gas mass flow rate ratio, fraction of steam extraction from the exhaust of LP line in HRSG for the generator of absorption and inlet LP and HP steam turbine temperature on the performance of power plant. Finally, the relative benefits of using absorption cooling over mechanical vapor compression (MVC) cooling in combined cycle power plant and its role in improvement of power plant efficiency is demonstrated (Hadizadeh et al. 2017).

Kaddari et al (2017) presents potential energy savings by installing high-efficiency motors instead of existing ones and their impact on greenhouse gases emissions reductions. In the literature, the focus has been mainly on separate and away electric motors from operating facilities. The main results of the study than other studies are that it applied the real motor's efficiency in the experiment. Finally the energy saving was about $12.6 \%$ at the operating value. The obtained findings show decrease in greenhouse gas emission up to 1,423 tons annually. The data analysis shows energy losses often generated by the degradation and rewinding of electrical motors. So the study show very interesting results that will contribute energy directors of industrial plants to become more involved in energy efficiency strategies (Kaddari et al, 2017).

Adeoye and Bamisaye (2016) declared the importance of the generating aspect cannot be over emphasized because the inevitable being played by this component of power system. They evaluate and analyses the performance of Omotoso Power Plant from the year 2008 to 2012 based on performance indices such as thermal and overall efficiencies. The intervals of outages of the power plant were investigated according to the information that was calculated from the outage log books. The study was performed using simple mathematical equations and data collection. This showed that the average values for thermal efficiency and overall efficiency of the generating plant was calculated to be $28.39 \%$ and $29.12 \%$ respectively due to different factors such as: break down or failures, obsolete technology, instability of the national grid system, ageing of plant components and disruption of gas supply (Adeoye and Bamisaye, 2016). 
Umrao et al (2017) show there is urgent need for optimal utilization of existing capacities by efficiently running of thermal power stations and saving energy used as fuel or auxiliary power for running the installations. They determining the actual performance of a coal based $210 \mathrm{MW}$ power plants at full and part loads (210 MW and 195.86 MW). Developing actual tasks of boiler efficiency, certain fuel consumption, heat value and total efficiency are evaluated. Within real performance, in addition to small deviations are shown from design amounts, they may result in substantial loss of revenue and excess operating expenditure. The possible issues for deterioration are analyzed and some possible remedies are suggested (Umrao et al, 2017).

Srinivas et al (2017) presents briefly on the boiler efficiency evaluation procedures by direct and indirect methods useful in thermal power plants. In the straight strategy, attention paid to the value of heat used so investigating the efficiency of the boiler, as well as non-straight strategy consider for different heat losses. The boiler efficiency investigated by straight strategy is found to be lower than that investigated by non-straight strategy as per the ASME PTC-4.1 standards. So, the straight strategy contributes the plant personnel to investigate quickly the boiler efficiency with few parameters and less instrumentation (Srinivas et al, 2017).

Shrivastava et al (2017) show performance improvement of very small amount can lead to large contribution in financial terms, which can be utilized for capacity addition to reduce demand supply gap. Coal fired thermal power plants are main sources of electricity in India. They has been evaluated relative technical efficiency of 60 coal fired power plants and compared using CCR and BCC models of data envelopment analysis. Target criteria of input variables have been investigated. Comparison of task such as small against medium against large power plants as well state owned against central owned against private owned. The findings show that poor efficiency of few power plants because of over use of input sources. The findings show that efficiency of small size power plants is less than medium and large sze power plant as well efficiency of state power plants is comparatively less than central and private power plant. The findings show that various criteria improve technical efficiency of the plants (Shrivastava et al, 2017).

Satish and Raju (2016) evaluated high energy cost and the necessity to reduce it, as well as environmental issues, optimized use of energy and energy consumption management are very important. In fact, by accurate thermodynamic analysis of thermal systems, we can obtain results for planning and optimizing energy. For this purpose, we need a data analysis instrument, which we may find in two laws of thermodynamic. The first law deals with energy analysis, and the second addresses irreversibility and exergy (Satish and Raju, 2016).

Dubey and Mishra (2017) refer to large amount of heat is transferred between all utilities of thermal power plant and it's greatly affect the plant performance. The First Law of Thermodynamic (FLT) is a quantitative evaluation of energy, it treats the work and heat interaction with equivalent forms of energy between system and surrounding. The FLT does not provide the information about internal losses, thermal inefficiency due to high grade energy of plant dump into the atmosphere and sustainability. The real performance of thermal system and quality of the energy transfer process estimated by the approach of the Second Law of Thermodynamic (SLT) called concept of exergy (Dubey and Mishra, 2017).

Lam and Shiu (2004) in China, the State Power Corporation (SPC) dominated the electric power sector. Our results from the data envelopment analysis (DEA) approach show that the total factor productivity (TFP) growth between 1995 and 2000 is 2.1 percent per year on average. Technological change accounts for almost all the TFP growth. Municipalities and coastal provinces have achieved higher technical efficiency and TFP growth during the period under study. Fuel efficiency and capacity utilization rate are significant factors affecting technical efficiency of power generation. 
(Lam and Shiu, 2004).

Yang et al compared conventional and advanced approach of exergy analysis of supercritical coal thermal power plant. Conventional approach identified the exergy destruction of all components, whereas advanced exergy analysis concludes thermodynamic interactions among thermal utilities for energy saving potential (Yang et al, 2013)

Ahmadi and Dincer analysed efficiency of dual pressure combined cycle power plant (CCP), 1st law and 2nd law thermodynamic efficiencies are reduced with the addition of the duct burner to HRSG, but power output of CCPP is improved (Ahmadi and Dincer, 2011).

A power plant in addition to other energy conversion technology, exergetic analysis methods is applied to determine the irreversibilities, or exergy destruction, in the system components. Developed exergetic analysis methods show that the irreversibilities during a component can be examined in two parts. The first section is due to irreversibilities in the component and it is referred to as the endogenous exergy destruction (Brown, 2015)

Considering the importance of thermal power plants (steam, gas and combined cycle) as the main sources of power generation in Iran, the purpose of this study was to investigate the new and advanced energy conversion technologies to measure technical efficiency and productivity in the analysis of power plants as one of the main elements of the cycle of power plant improvement in 10 active thermal power plants at the country in the year 2011-2016.

\section{MEASUREMENT OF TECHNICAL EFFICIENCY BY DATA ENVELOPMENT ANALYSIS (DEA)}

The use of the DEA model for the relative evaluation of units requires determining two basic characteristics, the nature of the pattern, and the return to the pattern scale, which are described below. The nature of the pattern used:

- Input nature: if we try to minimize inputs by keeping the output level constant in the evaluation process, the nature of the input pattern is the same.

- Output nature: if in the evaluation process, by keeping the input level constant, we try to increase the output level, the nature of the pattern used is the output.

In the DEA model, with the input view, we seek to obtain technical inefficiency as a proportion that must be reduced in inputs so that the output remains unchanged and the unit reaches to the efficient frontier. In the output view, we are looking for a ratio where outputs must be increased, without changing inputs, so that the unit reaches the efficiency boundary (Coelli \& Battese, 2005).

The return to scale represents the correlation between the input changes and the outputs of a system. One of the capabilities of the DEA method is the application of different patterns corresponding to return to different scales, as well as return to scale measurements for units.

- Constant Return to Scale: it means every number of inputs produces the same number of outputs. The CCR model assumes a return to scale of units constant. So, the small and large units are compared together.

- Variable Returns to Scale: that is, any number of inputs can produce the same output multiples of or less than or equal to outputs. The BCC model assumes that returns to scale are variable (Coelli \& Battese, 2005).

The CCR model has a constant return to scale, and try to choose the optimal weights for the input and output variables of the unit under consideration, and the efficiency of this unit (zero unit) increases so that the efficiency of other 
units do not exceed the upper limit 1 . This pattern is presented in two types of input and output natures, and in three fractional, multiplicative, and covert forms, and then, in the different forms in expressing the nature of the input.

$$
\operatorname{Max}: \frac{\sum_{r=1}^{s} u_{r} y_{r o}}{\sum_{i=1}^{m} v_{i} x_{i o}}
$$

s.t.

$$
\begin{aligned}
& \frac{\sum_{r=1}^{s} u_{r} y_{r j}}{\sum_{i=1}^{m} v_{i} x_{i j}} \leq 1, j=1,2, \ldots, n \\
& u_{r} \geq 0, v_{i} \geq 0
\end{aligned}
$$

The above-mentioned fractional planning model is known as the CCR fractional model, in which: ${ }_{r}$, the weight of the output is $\mathrm{R}^{\text {th }} ; v_{i}$ the input weight of the $\mathrm{i}^{\text {th }}$; and $O$ the decision maker unit is under consideration $(o \in\{1,2, \ldots, n\}) . y_{r o}$ and $x_{i o}$, respectively, the values of the output of the $\mathrm{r}^{\text {th }}$ and input of the $\mathrm{i}^{\text {th }}$ for the unit $\mathrm{i}^{\text {th }}$ under consideration ( $O$ unit). Also, ${ }^{y_{r j}}$ and ${ }^{x_{i j}}$ respectively, are the values of the output of the $\mathrm{r}^{\text {th }}$ and the input of the $\mathrm{i}^{\text {th }}$ for the unit $\mathrm{j}^{\text {th. }} \mathrm{S}$ is the number of outputs; $\mathrm{m}$; the number of inputs; and $\mathrm{n}$ also indicates the number of units. Note that the definition of efficiency in the CCR fractional model is "the result of dividing the weight composition of the combinations of outputs to the weight composition of inputs".

In this case, the total technical efficiency is divided into two components of net technical efficiency (managerial efficiency) and scale efficiency.

\section{Total Technical Efficiency= Net Technical Efficiency $($ Managerial Performance $) \times$ Scale Efficiency}

In the BCC model, there is variable return to scale assumption. The use of variable returns to scale makes it possible to provide a very accurate analysis by calculating the technical efficiency in terms of the scale efficiency and management efficiency. Input and output oriented models in the basic BCC model using the same principles of the CCR model and in the input-oriented model increases the efficiency by decreasing inputs, but in the output -oriented model, the efficiency increases with increasing output.

$$
\begin{aligned}
& \operatorname{Min} Z_{0}=\sum_{i=1}^{m} V_{i} x_{i 0}+w \\
& s t: \\
& \sum_{r=1}^{\delta} u_{r} y_{r 0}=1 \\
& -\sum_{r=1}^{\delta} u_{r} y_{r j}+\sum_{i=1}^{m} V_{i} x_{i 0}+w \geq 0, j=1,2, \ldots, n \\
& u_{r}, v_{i} \geq \mathcal{E}
\end{aligned}
$$




\subsection{Productivity}

Productivity is one of the important concepts for the study of performance over time. The productivity index is based on a binary comparison, which mainly refers to comparing the efficiency of a firm in two different times. The Malmquist index is defined for period's $t$ and $t+1$ as follows.

$$
\begin{aligned}
& M_{i}^{t+1}=\frac{d_{i}^{t+1}\left(y^{t+1}, x^{t+1}\right)}{d_{i}^{t}\left(y^{t}, x^{t}\right)}\left[\frac{d_{i}^{t}\left(y^{t+1}, x^{t+1}\right)}{d_{i}^{t+1}\left(y^{t+1}, x^{t+1}\right)} \times \frac{d_{i}^{t}\left(y^{t}, x^{t}\right)}{d_{i}^{t+1}\left(y^{t}, x^{t}\right)}\right] \\
& =E^{t+1} \times T^{t+1}
\end{aligned}
$$

In which $\mathrm{M}^{\mathrm{t}+1}$ is changes in the total productivity, $\mathrm{E}^{\mathrm{t}+1}$ is the changes in efficiency, and $\mathrm{T}^{\mathrm{t}+1}$, is technological changes are measured by the transition in the boundary production function between the periods $t$ and $t+1$. The above analysis is based on the assumption of constant returns to scale. In the case of assuming a variable return to scale, the efficiency changes also differ in their components, namely, the changes in the net technical efficiency (managerial efficiency) and the scale efficiency changes

\section{Total Productivity Changes $=$ Managerial Efficiency Changes $\times$ Scale Efficiency Changes $\times$ Technological Changes}

According to relation 4, for each firm, four distance of production factor must be calculated. In the conditions of constant returns to scale, and for the underlying firm (zero firm), these four functions can be represented in the form of the distance function of the production factors with $\mathrm{d}^{1}$ in the form of 5,6,7 and 8 relations presented, for which $\theta$ is free sign, $\lambda_{i} \geq 0$ and $(j=0,1,2, \ldots, n)$ is defined.

$$
\begin{aligned}
& {\left[d_{i}^{t+1}\left(y^{t+1}, x^{t+1}\right)\right]=\min \theta} \\
& \sum_{j=0}^{n} \lambda_{i} y_{i j, t+1} \leq y_{i, t+1} \quad(\mathrm{r}=1,2, \ldots \ldots, \mathrm{s}) \\
& \sum_{j=0}^{n} \lambda_{i} x_{i j, t+1} \leq \theta x_{i, t+1} \\
& {\left[d_{i}^{t+1}\left(y^{t+1}, x^{t+1}\right)\right]=\min \theta} \\
& \sum_{j=0}^{n} \lambda_{i} y_{i j, t+1} \leq y_{i, t+1} \\
& \sum_{j=0}^{n} \lambda_{i} x_{i j, t+1} \leq \theta x_{i, t+1} \quad(\mathrm{r}=1,2, \ldots \ldots, \mathrm{m}) \\
& {\left[d_{i}^{t+1}\left(y^{t+1}, x^{t+1}\right)\right]=\min \theta \quad(\mathrm{r}=1,2, \ldots \ldots, \mathrm{s})} \\
& \sum_{j=0}^{n} \lambda_{i} y_{i j, t+1} \leq y_{i, t+1} \quad \quad(\mathrm{r}=1,2, \ldots \ldots, \mathrm{m})
\end{aligned}
$$$$
\sum_{j=0}^{n} \lambda_{i} x_{i j, t+1} \leq \theta x_{i, t+1} \quad \quad(\mathrm{r}=1,2, \ldots \ldots, \mathrm{m})
$$$$
\sum_{j=0}^{n} \lambda_{i} x_{i j, t+1} \leq \theta x_{i, t+1} \quad \quad(\mathrm{r}=1,2, \ldots \ldots, \mathrm{m})
$$ 


$$
\begin{array}{lr}
\sum_{j=0}^{n} \lambda_{i} x_{i j, t+1} \leq \theta x_{i, t+1} & (\mathrm{r}=1,2, \ldots \ldots, \mathrm{m}) \\
{\left[d_{i}^{t+1}\left(y^{t+1}, x^{t+1}\right)\right]=\min \theta} & \\
\sum_{j=0}^{n} \lambda_{i} y_{i j, t+1} \leq y_{i, t+1} & (\mathrm{r}=1,2, \ldots \ldots, \mathrm{s}) \\
\sum_{j=0}^{n} \lambda_{i} x_{i j, t+1} \leq \theta x_{i, t+1} & (\mathrm{r}=1,2, \ldots \ldots, \mathrm{m})
\end{array}
$$

In order to applied variable efficiency, limitation of $\sum_{j=0}^{n} \lambda_{i}=1$ will be added.

\section{MODEL DESCRIPTION}

This research in term of nature is empirical, due to limitations such as being newly established, non-utilization of full capacity, limiting access to the number of employees and lack of transparency in the information of most active thermal power plants in the country, only it was possible to measure technical efficiency and productivity at 10 steam, gas and combined cycle power plants. Shahid Firoozi, Zarand, Shahid Mofateh, Orumieh, Shiraz, Booshehr, Gilan, Qom, Rey, Fars are responsible for $42 \%$ of the special power production of the Ministry of power plants in 2016 (Detailed statistics of Iran's power industry, 2016), and they are considered as a decision maker unit which uses 3 fuel inputs, labour, and installed capacity for electricity production. The statistics and information about each of the above variables are compiled using the library methodology in time period 2012-2016 from the detailed statistics of Iran's power industry, which is published annually by Thermal Power Plant Holding. As outlined in theoretical foundations, measurement of the efficiency of homogeneous firms relative to each other is an obvious feature of data envelopment analysis (DEA) method. In this study, firms such as steam, gas and combined cycle power plants that have similar inputs, outputs, structure and mechanism are assumed to be homogeneous. Therefore, uncontrolled environmental and geographic factors can be ignored due to the same impact on power plants, and a data envelopment analysis (DEA) method is used to measure the efficiency of these power plants.

After collecting the necessary statistics and information, the technical efficiency measurements of these ten steam, gas and combined cycle power plants using the two-step data envelopment analysis (DEA) method (relation 3) with two assumptions of constant and variable returns to scale are discussed. First, the technical efficiency of these power plants is separately measured in each section of the year in 2011-2016. After measuring the technical efficiency of power plants annually, the results of the 2016 year are interpreted as the last year and the results obtained in other years are used only to meet goals such as measuring the effectiveness of managerial and scale inefficiency in the technical inefficiency in 2012-2016. Then, the process of changes in the productivity of total factor of production of these plants and its components (changes in net technical efficiency, changes in scale efficiency and technological changes) is estimated using the compile data for the period of 2012-2016 and the Malmquist index (model 4). Therefore, in this study, Win4DEAP software has been used to measure technical efficiency and productivity through data envelopment analysis (DEA) and Malmquist index. 


\section{RESULTS}

\subsection{The Average Managerial and Scale Efficiency in 2012-2016}

Figure 1 shows the average managerial and scale efficiency of power plant for each of the years 2012-2016 separately.

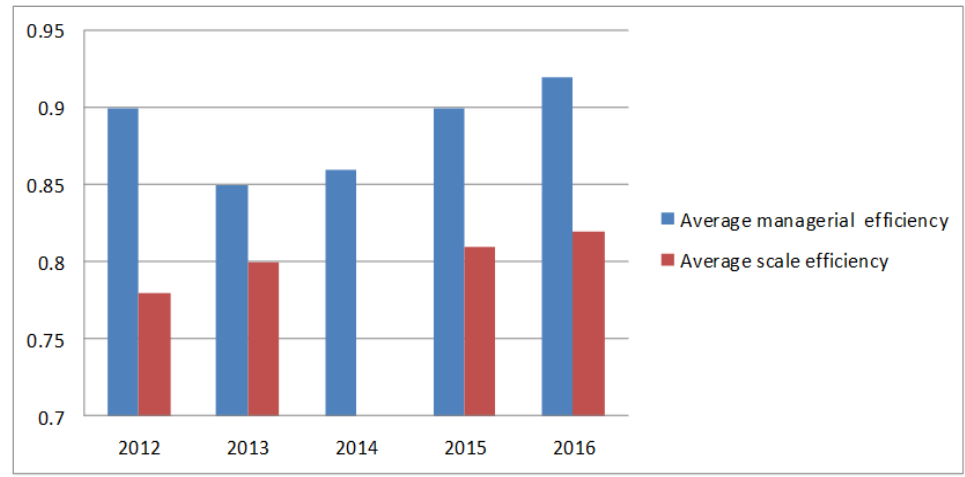

Figure 1: Average Managerial and Scale Efficiency in 2012-2016

According to figure 1, in the years under review, the scale efficiency is less than managerial efficiency. Therefore, it can be concluded that the inefficiency of the scale has the greatest impact on technical inefficiency under the assumption of CRS. This means that most power plants do not consider the importance of production on an optimal scale.

\subsection{Comparison of Technical Efficiency of Steam, Gas and Combined Cycles Power Plants}

Figures 2 and 3 show the average technical efficiency of each power plant in 2012-2016 under both assumptions of constant and variable returns to scale. As these figures show, in all of the years under consideration, combined cycle power plants have a higher average technical efficiency than other power plants.

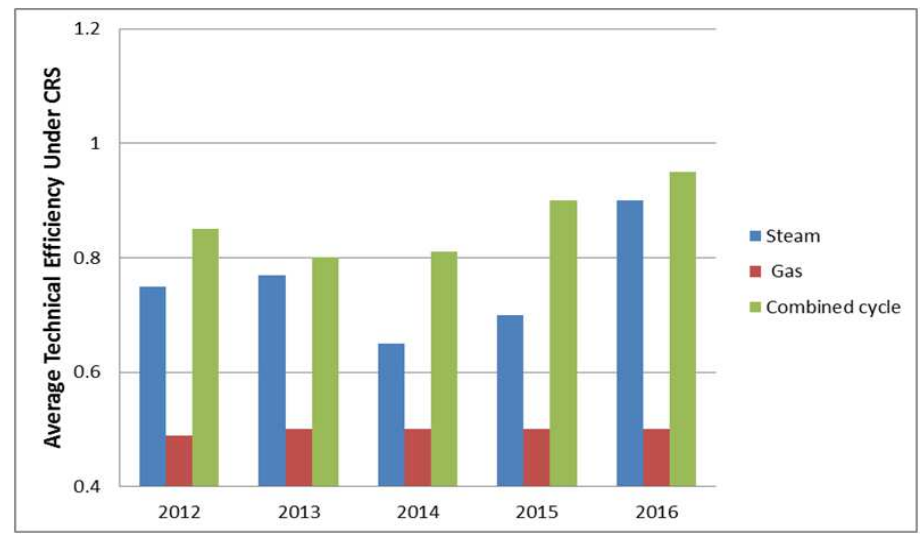

Figure 2: Average Technical Efficiency of Steam, Gas and Cyclic Power Plants under the Assumption of CRS 


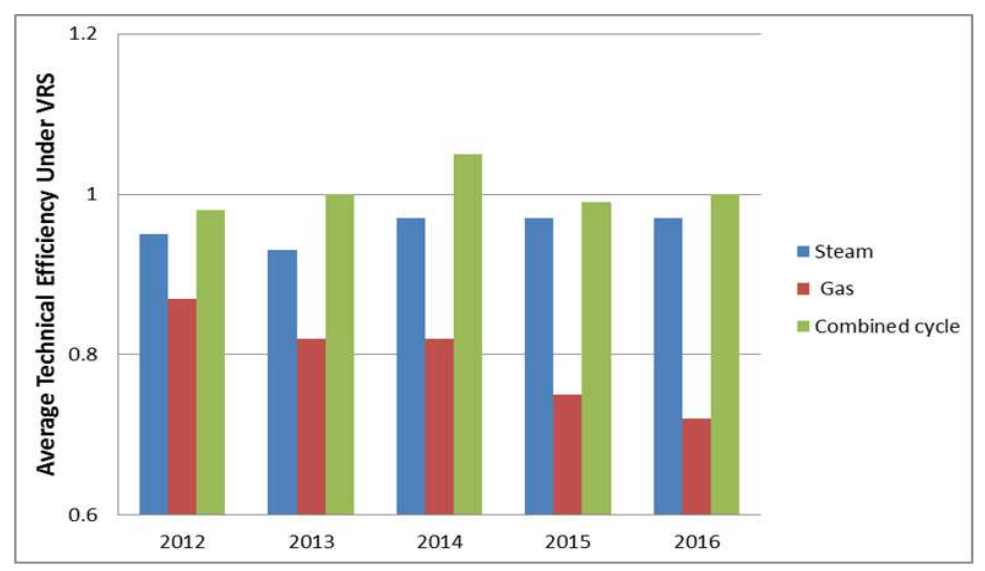

Figure 3: Average Technical Efficiency of Steam, Gas and Cyclic Power Plants under the Assumption of VRS

\subsection{Measurement of Productivity Using the Malmquist Index}

According to figure 4, which shows the geometric average of the total productivity changes of the factors of production in 2012-2016, it observed that 10 power plants discussed in this study, 6 power plants have an average positive productivity growth and 4 power plants had a negative growth in productivity over the years.

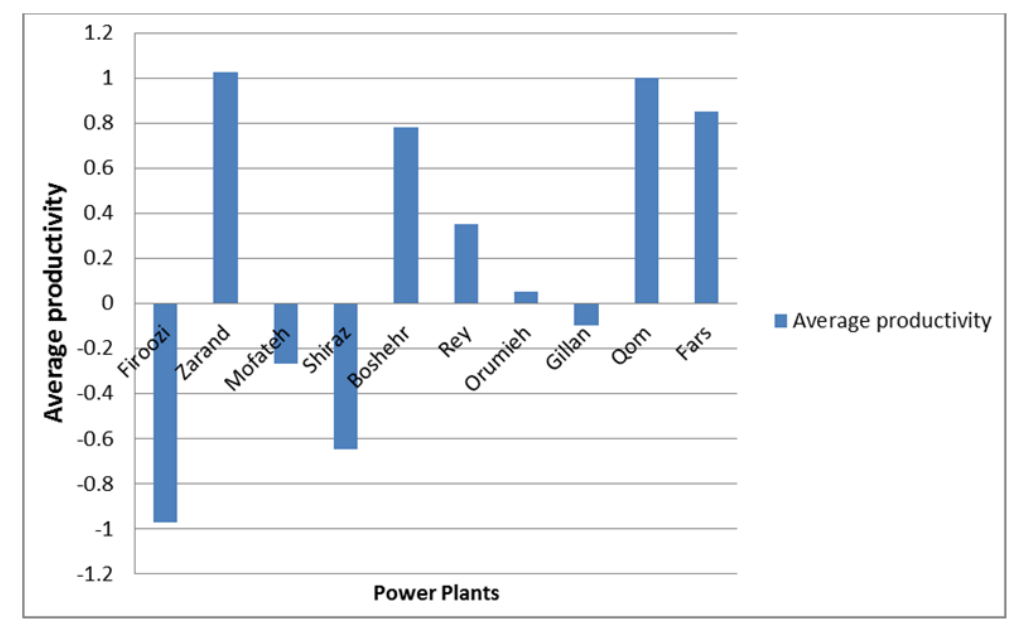

Figure 4: Geometric Mean of Productivity Changes of the Studied Power Plants in 2012-2016

According to Table 4, the average productivity growth of all power plants is $1.8 \%$. Zarand, Qom and Fars power plants had the highest productivity growth rate of 5.5, 4.9 and 4.2.8 percent, respectively. Shahid Firoozi, Shiraz and Shahid Mofateh power plants have negative performance among the power plants with a negative growth rate of $-2.1,-1.8$ and -1.2 respectively. Changes in net technical efficiency examined for all power plants over the years 2012-2016 which show an average positive growth rate of $0.4 \%$. Zarand and Qom power plants with average annual growth of 5.5 and 4.9 had the highest percentage of positive growth and Firoozi and Shiraz power plants with -2.1 and -1.8 percent respectively, have the most negative growth among the studied power plants. This condition implies that these plants do not have the incentive to reduce the utilization of factors of production or promote efficiency and productivity. This may be due to the fact that these plants are generally state-owned and operate in a market that is monopolistic and not competing. In addition, with government subsidies has ease of access to production factors such as fuel. 
Table 4: Changes in Productivity and its Components on Average in 2012-2016

\begin{tabular}{|c|c|c|c|c|}
\hline \multirow{2}{*}{$\begin{array}{l}\text { Power } \\
\text { Plants }\end{array}$} & \multicolumn{2}{|c|}{ Average Changes } & \multirow{2}{*}{$\begin{array}{c}\text { Average } \\
\text { Changes in } \\
\text { Technology }\end{array}$} & \multirow{2}{*}{$\begin{array}{c}\text { Average } \\
\text { Changes in } \\
\text { Productivity }\end{array}$} \\
\hline & $\begin{array}{l}\text { Net Technical } \\
\text { Efficiency }\end{array}$ & $\begin{array}{c}\text { Scale } \\
\text { Efficiency }\end{array}$ & & \\
\hline Firoozi & 0.990 & 0.948 & 1.02 & 0.959 \\
\hline Zarand & 0.998 & 0.987 & 0.995 & 1.000 \\
\hline Mofateh & 0.974 & 0.997 & 1.000 & 0.986 \\
\hline Rey & 1.000 & 0.989 & 0.986 & 0.995 \\
\hline Orumieh & 0.995 & 0.986 & 0.987 & 0.989 \\
\hline Shiraz & 0.973 & 0.989 & 0.999 & 0.975 \\
\hline Booshehr & 1.002 & 1.003 & 0.986 & 1.010 \\
\hline Gillam & 0.990 & 0.982 & 0.996 & 0.986 \\
\hline Qom & 0.986 & 0.986 & 1.007 & 1.015 \\
\hline Fars & 0.990 & 0.990 & 1.006 & 1.010 \\
\hline
\end{tabular}

Table 4 shows that the scale efficiency changes in the studied power plants in the given period have an average annual growth of $0.4 \%$. Among the studied power plants, Booshehr power plant with $4.5 \%$ positive growth in efficiency had the best scale efficiency and Shahid Firoozi power plant with $-3.8 \%$ negative growths in scale efficiency had the worst efficiency.

The best part of the changes in the productivity of the power plants is the technological change (technical progress), which has an average annual growth of around $0.5 \%$, which means that, as the equipment and facilities are advanced for power generation, due to the high cost of switching equipment with advanced imports equipment and lack of incentives to use advanced technologies to minimize the use of production inputs, especially fuel, most power plants have not used enough equipment to improve efficiency and productivity.

According to table 5, changes in technical efficiency of studded power plants (which are obtained from the net technical efficiency of the scale efficiency) and technological changes are 0.78 and 0.96 percent, respectively. So it was concluded that total productivity changes are more likely to be due to technical efficiency changes. On average, $56.8 \%$ of the total productivity changes are from the area of technical efficiency changes and the remaining $48.9 \%$ are due to technological changes. In the case of the separation of technical efficiency changes, the share of each of the changes in the net technical efficiency, the changes in the efficiency of the scale, and the technological changes in total productivity changes are 19.8 and $21.1,36.42$ respectively. Therefore, the most influential factor in the productivity changes in the studied power plants is technological change, which also has a modest annual growth rate.

Table 5: Changes in Productivity and its Components in 2012-2016

\begin{tabular}{|l|c|c|c|c|c|}
\hline \multirow{2}{*}{ Changes } & \multicolumn{5}{|c|}{ Time Period } \\
\cline { 2 - 6 } & $\mathbf{2 0 1 2 - 2 0 1 3}$ & $\mathbf{2 0 1 3 - 2 0 1 4}$ & $\mathbf{2 0 1 4 - 2 0 1 5}$ & $\mathbf{2 0 1 5 - 2 0 1 6}$ & Average \\
\hline $\begin{array}{l}\text { Changes in net } \\
\text { technical efficiency }\end{array}$ & 0.978 & 1.016 & 0.975 & 0.994 & 0.999 \\
\hline $\begin{array}{l}\text { Changes in scale } \\
\text { efficiency }\end{array}$ & 1.002 & 0.997 & 0.970 & 0.990 & 1.032 \\
\hline $\begin{array}{l}\text { Changes in } \\
\text { technology }\end{array}$ & 1.029 & 0.988 & 0.995 & 0.960 & 0.978 \\
\hline $\begin{array}{l}\text { Changes in total } \\
\text { productivity }\end{array}$ & 1.029 & 1.023 & 1.048 & 1.048 & 1.122 \\
\hline
\end{tabular}




\section{CONCLUSIONS}

The results of the study of the technical efficiency of 10 power plants show that the average technical efficiency of the power plants in 2016 under the assumption of VRS and CRS was 84.2, 89.8\%, respectively. Zarand, Qom and Fars power plants have been introduced as reference plants. Inefficient power plants are advised to improve their technical efficiency by reducing their use of inputs provided that they are stable in the specific production of electricity with the coefficients proposed by the reference power plants in addition to modifying the pattern of consumption of inputs on an efficient frontier. The scale inefficiency has had the greatest impact on the technical inefficiency under the CRS assumption. This means that most of the plants are not considered production on an optimal scale. The plants that operate in the ascending and descending returns to the scale process increase and decrease their activity levels in order to move towards the flat long term average of cost (optimal scale). In these years, under both VRS and CRS assumptions, combined cyclic power plants had a higher average technical efficiency than other power plants. It is recommended that power plants that use only gas turbines to generate electricity to improve the efficiency will move toward the combined cycle. This means that a gas turbine will be used alongside the gas turbine. On average, the productivity growth of all power plants in the years 2012-2016 was $1.8 \%$, which indicates a slight growth. Changes in net technical efficiency, changes in scale efficiency and technological changes during the study period, for all the plants, had a positive growth of $0.4,0.38$ and 0.78 , respectively. The most influential factor in the changes in the efficiency of selected plants is technological change, which has had a slight annual growth. Therefore, in order to increase technical efficiency and technological progress and ultimately increase productivity, it is suggested that power plants provide education, advice and promotion of new technologies. During the period under study, productivity changes have not undergone a certain trend, so that in some years growth has been negative and in others it has experienced positive growth over many years. The proposed method in this paper well covers the computational layer of the productivity improvement cycle. Therefore, it is recommended that not only power plants but other sectors of the power industry (transmission and distribution) also use this method of measuring productivity, and it is hoped that the results of these calculations will be the basis for proper and practical planning for increasing the productivity and efficiency of the electricity industry.

\section{REFERENCES}

1. R. Wolfson, "Electricity" in Energy, Environment, and Climate, 2nd ed., New York, NY: W.W. Norton \& Company, 2012, ch. 11, sec. 1, pp. 292

2. R. Mahamud, M.M.K. Khan, M.G. Rasul and M.G. Leinster (2013). Exergy Analysis and Efficiency Improvement of a Coal Fired Thermal Power Plant in Queensland. Thermal Power Plants - Advanced Applications.

3. Chenxi Song, Mingjia Li, Fan Zhang, Yaling He, Wenquan Tao (2014). Analysis of Energy Efficiency for Coal-fired Power Units based on Data Envelopment Analysis Model. The 6th International Conference on Applied Energy - ICAE2014. Energy Procedia 61 ( 2014 ) $904-909$.

4. Tser-Yieth Chen, Tsai-Lien Yeh, and Yi-Ting Lee (2013). Comparison of Power Plants Efficiency among 73 Countries. Journal of Energy Volume 2013 (2013), Article ID 916413, 8 pages http://dx.doi.org/10.1155/2013/916413

A. Hadizadeh, B. Paknafs, M. Javaherdeh and H. Naghashzadegan (2017). Evaluating and improving the efficiency of steam power plants using chillers. Mechanics \& Industry, 182 (2017) 213.

5. Mohamed Kaddari, Mahmoud El Mouden \& Abdelowahed Hajjaji (2017). Evaluation of energy savings by using high efficiency motors in a thermal power station. Journal International Journal of Green Energy Volume 14, 2017 - Issue 10 
6. Adeoye OS, Bamisaye AJ (2016) Performance Evaluation and Analysis of Omotoso Power Plant 2016 in Nigeria. Innov Ener Res 5:134. doi:10.4172/ier.1000134

7. Umrao OP, Kumar A, Saini VK (2017) Performance of Coal Based Thermal Power Plant at Full Load and Part Loads. Global J Technol Optim 8: 205. doi: 10.4172/2229-8711.100020

8. Gudimella Tirumala Srinivas, Doddapineni Rajeev Kumar, Peruri Venkata Vithal Murali Mohan, Boggarapu Nageswara Rao. Efficiency of a Coal Fired Boiler in a Typical Thermal Power Plant. American Journal of Mechanical and Industrial Engineering. Vol. 2, No. 1, 2017, pp. 32-36. doi: 10.11648/j.ajmie.20170201.15

9. Shrivastava, Naveen \& Sharma, Seema \& Chauhan, Kavita. (2011). Efficiency assessment and benchmarking of thermal power plants in India. Energy Policy - ENERG POLICY. 40.. 10.1016/j.enpol.2011.09.020.

10. V.Satish and V.Dhana Raju (2016). Energy and Exergy Analysis of Thermal Power Plant. International Journal of Engineering Science and Computing, Volume 6 Issue No. 8

11. Kaushalendra Kumar Dubey and R. S. Mishra (2017). Thermodynamic (Energy-Exergy) Analysis Of Nine MW Coal Based Thermal Power Plant Using Entropy Generation Principle. American Journal of Engineering Research (AJER). Volume-6, Issue-7, $p$ - $52-57$

12. Pun-Lee Lam and Alice Shiu (2004). Efficiency and Productivity of China's Thermal Power Generation. Review of Industrial Organization, 2004, vol. 24, issue 1, 73-93

13. Y.Yang, L.Wang, C.Dong, G.Xu, T.Morousk and G.Tsatsaronis "Comprehensive exergy based evaluation and parametric study of a coal-fired ultra supercritical powerplant”.Applied Energy,2013.

14. P. Ahmadi and I. Dincer "Thermodynamic analysis and Thermoeconomic optimization of a dual pressure combined cycle power plant with supplementary firing unit" Energy Conversion Management,52,pp 2296-308,2011

15. Corey j. Brown (2015). Advanced exergy and exergoeconomic analysis of the major components of a combined cycle power plant. Submitted to the Office of Graduate and Professional Studies of Texas A\&M University in partial fulfillment of the requirements for the degree of master of science.

16. Coelli, T. J., Rao, D. S. P., O’donnell, C. J., Battese, G. E. (2005), An introduction to efficiency and productivity analysis, Second Edition, Springer. 
